\title{
Asset Liquidity Adjusted VaR
}

\section{Dr. Viviane Y Naimy*}

Professor of Finance, Faculty of Business Administration and Economics, Notre Dame University, Louaize, Lebanon

Liquidity risk is divided into asset liquidity risk and funding liquidity risk. The first one, known as market/product-liquidity risk arises when a forced liquidation of assets creates unfavorable price movements. This risk varies across categories of assets and across time as a function of prevailing market conditions. It can be managed by setting limits on certain markets or products and by means of diversification. Liquidity risk can be factored into $\mathrm{VaR}$ measures by ensuring the horizon is at least greater than an orderly liquidation period.

Funding-liquidity risk or cash-flow risk refers to the inability to meet payments obligations, which may force early liquidation. This constitutes a problem for portfolios that are leveraged and subject to margin calls from the lender. Funding-risk can be controlled by setting limits on cash-flow gaps, by diversification, and by consideration of how new funds can be raised to meet cash shortfalls.

Liquidity needs are uncertain. A great deal of research is still going on to model liquidity risk and measure its effects when managing other types of risks. Discussion has begun on the creation of liquidity risk derivatives allowing parties to trade liquidity risk. The 2007 credit crisis has emphasized the importance of liquidity risk for financial institutions and regulators. Financial institutions are required to assess worst-case liquidity scenario and make sure that they can overcome that scenario by either converting assets into cash or borrowing fund externally. Basel III requirements are well tailored to ensure that banks do this [1].

The question in this editorial paper is to study how VaR can be adapted to deal with asset liquidity considerations [2].

The process of assessing asset liquidity risk starts with focusing on the various components of liquidation costs. The first and most easily measurable is the quoted bid-ask spread, defined in relative terms as $S$ where

$$
S=[P(\text { ask })-P(\text { bid })] / P(\text { mid })
$$

Spreads vary from a low of about $0.05 \%$ for major currencies, large US stocks, and on-the-run Treasuries to much higher values when dealing with less liquid currencies, stocks, and bonds. Spreads depend also on market conditions. Spreads reflect three different types of costs according to market microstructure theory: order-processing costs, asymmetric-information costs, and inventory carrying costs.

A simple way to measure the cost of liquidating a position in an asset in a normal market conditions, is to consider the cost equal

$$
\sum_{i=1}^{n} \frac{1}{2} s_{i} \alpha_{i}
$$

Where $\mathrm{n}$ is the number of positions,

$\alpha_{i}$ is the position in the $i^{\text {th }}$ instrument, and

$S_{i}$ is the proportional bid-offer spread for the $i^{\text {th }}$ instrument.

Although diversification reduces market risk, it does not reduce liquidity trading risk. It is worth noting that $S_{\mathrm{i}}$ increases with the size of position $i$. holding many positions tends to entail less liquidity risk. Therefore as mentioned above, setting position limits is a strategy to decrease trading risk [3].
Another measure of liquidity is the cost of liquidation in stressed market conditions within a defined time period.

$$
\text { Cost of liquidation }=\sum_{i=1}^{n} \frac{1}{2}\left(\mu_{i}+\lambda \sigma_{i}\right) \alpha_{i}
$$

Where $\mu_{i}$ and $\sigma_{i}$ are the mean and standard deviation of the relative spread for the $i$ th financial instrument held,

$\lambda$ is the parameter that gives the required confidence level for the spread.

Equation (3) assumes that spreads of all instruments are perfectly correlated.

Once the spread are fixed, one simply could construct a liquidityadjusted VaR, LVAR, from the traditional VaR by adding the cost of unwinding positions in a normal market or a stressed market as suggested by Bangia et al. who in fact consider the uncertainty in the spread [4].

$$
\begin{aligned}
& \text { Liquidity - Adjusted } \mathrm{VaR}=\mathrm{VaR}+\sum_{i=1}^{n} \frac{1}{2} s_{i} \alpha_{i} \\
& \text { Liquidity-Adjusted stressed } \mathrm{VaR}=\mathrm{VaR}+\sum_{i=1}^{n} \frac{1}{2}\left(\mu_{i}+\lambda \sigma_{i}\right) \alpha_{i}
\end{aligned}
$$

This assumes that the worst market loss and increase in spread will occur simultaneously. In general we observe a positive correlation between volatility and spreads. At the portfolio level, one theoretically could take into account correlations between spreads. In practice, summing the individual worst spreads provides a conservative measure of the portfolio worst spread but in fact it is not. Because when liquidity is tight and spreads widen, they tend to do so for all instruments. Therefore it makes sense to calculate the liquidity measures in equation (2) and (3) on a regular basis which are likely to be decreasing functions of the liquidation time period.

\section{References}

1. Basel Committee on Banking Supervision, December 2010. Basel III: A Global Regulatory Framework for More Resilient Banks and Banking Systems.

2. Naimy V (2014) The German and French Stock Markets Volatility as Observed from the VaR Lens. Am J I Math Statistic, 4: 7-11.

3. Hull J (2012) Risk Management and Financial Institutions. 3d ed. Wiley.

4. Bangia A, Diebold F, Schuermann T, Stroughair J (1999) Liquidity on the Outside. Risk 12: 68-73.

*Corresponding author: Dr. Viviane Y. Naimy, Professor of Finance, Faculty of Business Administration and Economics, Notre Dame University, Louaize, Lebanon, E-mail: vnaimy@ndu.edu.lb

Received November 17, 2014; Accepted November 18, 2014; Published December 15, 2014

Citation: Naimy VY (2014) Asset Liquidity Adjusted VaR. J Bus Fin Aff 3: 129 doi:10.4172/2167-0234.1000129

Copyright: ( 2014 Naimy VY. This is an open-access article distributed under the terms of the Creative Commons Attribution License, which permits unrestricted use, distribution, and reproduction in any medium, provided the original author and source are credited. 